\title{
Education as Predictor of Low Birth Weight among Female Worker in Indonesia
}

\author{
Ina Kusrini $^{1}$, Noviati Fuada ${ }^{1}$, Sri Supadmi ${ }^{1}$, Agung Dwi Laksono ${ }^{2}$ \\ ${ }^{1}$ Researcher, Unit of Health Research and Development Magelang, Indonesia Ministry of Health, Central Java, \\ Indonesia, ${ }^{2}$ Researcher, Center of Research and Development of Humanities and Health Management, Indonesia \\ Ministry of Health, Jakarta, Indonesia
}

\begin{abstract}
Female workers are a vulnerable group in Indonesia because in addition to working to help their husbands earn a living, they also still have to be responsible for domestic affairs. This study aimed to analyze the effect of the level of education on the incidence of LBW in female workers in Indonesia. The analysis uses the 2017 Indonesian Demographic and Health Survey data. Stratification and multistage random sampling method get 18,061 female workers as respondents. The final stage was done using binary logistic regression. The results found that there was no difference between primary education female workers and no education female workers at the risk of giving birth to LBW babies. Secondary education female workers have a 0.561 times chance compared to no education female workers to give birth to LBW babies. Meanwhile, higher education female workers have a possibility of 0.414 times compared to no education female workers to give birth to LBW babies. Apart from the education level, the results of the analysis also found two other variables as predictors of LBW among female workers, namely wealth status and ANCvisits. It was concluded that the education level is a predictor of LBW among female workers in Indonesia. The higher the education level, the lower the possibility of female workers to have LBW babies in Indonesia.
\end{abstract}

Keywords: Low birth weight, female worker, education,maternal health, nutrition.

\section{Introduction}

Female workers are a group that is prone to various health-related risks ${ }^{1}$. In addition to exposure in the workplace, women who are also of childbearing age need optimal health conditions because it is a key element of intergenerational health ${ }^{2,3}$. Adequacy of nutrition for women, whether they are still in the status of young women, pre-pregnant adults, and even more so during pregnancy, are factors that directly contribute to the nutritional status of the children they will be born with ${ }^{4}$. A study conducted in several developing countries

\section{Corresponding Author:}

\section{Agung Dwi Laksono}

Researcher, Center of Research and Development of Humanities and Health Management, Indonesia Ministry of Health, Jakarta, Indonesia e-mail: agung.dwi.laksono-2016@fkm.unair.ac.id states that three socio-economic factors can explain the problem of child malnutrition, namely women's social status, sanitation, and urbanization. The positive influence of children's nutritional status is related to the role of women in decision-making and gender equality in society, in addition to caring for children and providing nutrition directly from mother to fetus ${ }^{5}$.

For this reason, the health of female workers is an important factor in achieving the goals of global health development. Globally, the female labor force participation rate is quite high (\% of female population ages $15+$ ), in 2019 it is estimated at $47.14 \%$. Meanwhile in Indonesia, the percentage of female workers is greater, namely 53\%in 2019 it is estimated at $47.14 \%$. Meanwhile in Indonesia, the percentage of female workers is greater, namely $53 \%{ }^{6}$. This means that most women in Indonesia are female workers, both in the formal and informal sectors. In general, women workers work in three sectors, namely education, health, and 
social workers ${ }^{7}$. The average profile of housewives in Indonesia is also a worker, although not as the main support for family economic activities. They work in agriculture, services, and trade with the status of helping their husbands or families.

Among the risk factors for women in the workplace were revealed by previous studies. A high workload and a lower wage than men are experienced by female workers on average. On average, women dedicate 3.2 times more working hours per day than men to unpaid work ${ }^{8}$. The International Labor Organization states that $76.2 \%$ of women do unpaid care work. Besides, exposure to environmental hazards, stress, and nutritional insufficiency. Various risks experienced by women have an impact on public health if they cannot be controlled optimally ${ }^{7}$. Previous studies revealed that $81 \%$ of children to working mothers have a higher risk of neonatal death when compared to children born to non-working mothers ${ }^{9}$. Female workers who experience malnutrition are at risk of producing malnourished babies. One of the indicators of malnutrition is the low birth weight (LBW), a previous study stated the relationship between female workers and the occurrence of $\mathrm{LBW}^{10,11}$.

LBW is currently the main cause of child mortality and mortality. Every year nearly 1.1 million babies die from complications of preterm birth. LBW is not only a major predictor of prenatal mortality and morbidity but also increases the risk of slower cognitive development, non-communicable diseases such as diabetes and cardiovascular disease later in life $^{7}$.Several studies suggest that LBW is associated with poverty and education indicators ${ }^{12,13}$.LBW had the consequence that they had to spend the first few days or weeks of life in the NICU. This is to ensure the baby's life is guaranteed with an artificial uterus. The risks of complications that can be suffered by LBW babies are the health consequences of LBW infants, thermoregulation, hypoglycemia, fluid and electrolyte imbalance, nutrition, hyperbilirubinemia, chronic lung disease, patent ductus arteritis, infections, necrotizing enterocolitis, intraventricular hemorrhage, apnea of prematurity, anemia, hearing and adult health problems ${ }^{14}$. Based on the background description, this study aims to analyze the effect of the level of education on the incidence of LBW in female workers in Indonesia.

\section{Materials and Method}

This research was employed with secondary data from the 2017 Indonesian Demographic Data Survey (IDHS). The analysis unit was female workers aged 1549 years old who had given birth in the last 5 years. The 2017 IDHS sampling method was done by stratification and multistage random sampling so that there were 18,061 female workers as respondents.

LBW is a birth weight of fewer than 2,500 grams (or 5.5 pounds). LBW is determined regardless of gestational age. Birth weight is the first birth weight of a newborn measured after birth ${ }^{15}$. The education level is the last certificate the respondent has. Other independent variables analyzed in this study were age group, marital status, wealth status, ANC visits, and smoking behavior.

The final stage for determining the education level as a predictor of LBW was done using binary logistic regression because of the nature of the dependent variable. All statistical analyzes were carried out using SPSS 22 software.

\section{Results and Discussion}

Table 1 shows descriptive statistics of the education level of female workers in Indonesia. It can be seen that all categories of education level are dominated by female workers who give birth to LBW babies, except for female workers who have higher education. Based on the age group, all education level categories were dominated by the 35-39 age group, except for female workers who had higher education, which was dominated by the $30-34$ age group.

Based on marital status, all education level categories are dominated by female workers who are married/living with partners. Meanwhile, based on wealth status, all categories of education level were dominated by the poorest female workers, except for female workers who had higher education, which was dominated by the richest. Based on the ANC visits, all education level categories were dominated by female workers who made complete ANC visits ( $\geq 4$ times) during pregnancy. Finally, based on smoking behavior, all education level categories are dominated by female worker smokers.

Table 2 shows the results of the binary logistic regression of LBW among female workers in Indonesia. It was found that there was no difference between primary education female workers and no education female workers at the risk of giving birth to LBW babies. Secondary education female workers are 0.561 times 
more likely than no education female workers to give birth to LBW babies (OR 0.561; 95\% CI 0.370-0.850). Meanwhile, higher education female workers have a 0.414 times chance compared to no education female workers to give birth to LBW babies (OR 0.414; 95\% CI 0.265-0.645). This information shows that the higher the education level, the lower the possibility of female workers to produce LBW babies in Indonesia.

Table 1. The descriptive statistics of the education level of the female workers who had given birth in the last 5 years in Indonesia $(n=18,061)$

\begin{tabular}{|c|c|c|c|c|c|c|c|c|c|}
\hline \multirow{3}{*}{ Variables } & \multicolumn{8}{|c|}{ Education Level } & \multirow{3}{*}{$\mathbf{P}$} \\
\hline & \multicolumn{2}{|c|}{ No Education } & \multicolumn{2}{|c|}{ Primary } & \multicolumn{2}{|c|}{ Secondary } & \multicolumn{2}{|c|}{ Higher } & \\
\hline & $\mathbf{n}$ & $\%$ & n & $\%$ & n & $\%$ & n & $\%$ & \\
\hline Low Birth Weight & & & & & & & & & $* * * 0.000$ \\
\hline No & 129 & $22.4 \%$ & 1524 & $28.5 \%$ & 3404 & $41.0 \%$ & 2047 & $53.6 \%$ & \\
\hline Yes & 448 & $77.6 \%$ & 3831 & $71.5 \%$ & 4905 & $59.0 \%$ & 1773 & $46.4 \%$ & \\
\hline Age group & & & & & & & & & $* * * 0.000$ \\
\hline $15-19$ & 3 & $0.5 \%$ & 20 & $0.4 \%$ & 72 & $0.9 \%$ & 0 & $0.0 \%$ & \\
\hline $20-24$ & 24 & $4.2 \%$ & 209 & $3.9 \%$ & 693 & $8.3 \%$ & 95 & $2.5 \%$ & \\
\hline $25-29$ & 51 & $8.8 \%$ & 635 & $11.9 \%$ & 1523 & $18.3 \%$ & 797 & $20.9 \%$ & \\
\hline $30-34$ & 104 & $18.0 \%$ & 1192 & $22.3 \%$ & 2190 & $26.4 \%$ & 1338 & $35.0 \%$ & \\
\hline $35-39$ & 157 & $27.2 \%$ & 1710 & $31.9 \%$ & 2215 & $26.7 \%$ & 1067 & $27.9 \%$ & \\
\hline $40-44$ & 157 & $27.2 \%$ & 1235 & $23.1 \%$ & 1318 & $15.9 \%$ & 413 & $10.8 \%$ & \\
\hline $45-49$ & 81 & $14.0 \%$ & 354 & $6.6 \%$ & 298 & $3.6 \%$ & 110 & $2.9 \%$ & \\
\hline Marital status & & & & & & & & & $* * * 0.000$ \\
\hline Never in union/Divorced/Widowed & 24 & $4.2 \%$ & 291 & $5.4 \%$ & 382 & $4.6 \%$ & 75 & $2.0 \%$ & \\
\hline Married/Living with partner & 553 & $95.8 \%$ & 5064 & $94.6 \%$ & 7927 & $95.4 \%$ & 3745 & $98.0 \%$ & \\
\hline Wealth status & & & & & & & & & $* * * 0.000$ \\
\hline Poorest & 481 & $83.4 \%$ & 2953 & $55.1 \%$ & 1833 & $22.1 \%$ & 268 & $7.0 \%$ & \\
\hline Poorer & 53 & $9.2 \%$ & 979 & $18.3 \%$ & 1694 & $20.4 \%$ & 386 & $10.1 \%$ & \\
\hline Middle & 25 & $4.3 \%$ & 731 & $13.7 \%$ & 1721 & $20.7 \%$ & 519 & $13.6 \%$ & \\
\hline Richer & 13 & $2.3 \%$ & 467 & $8.7 \%$ & 1706 & $20.5 \%$ & 866 & $22.7 \%$ & \\
\hline Richest & 5 & $0.9 \%$ & 225 & $4.2 \%$ & 1355 & $16.3 \%$ & 1781 & $46.6 \%$ & \\
\hline ANC visits & & & & & & & & & $* * * 0.000$ \\
\hline$<4$ times & 56 & $42.7 \%$ & 307 & $18.2 \%$ & 303 & $8.5 \%$ & 99 & $5.1 \%$ & \\
\hline$\geq 4$ times & 75 & $57.3 \%$ & 1383 & $81.8 \%$ & 3244 & $91.5 \%$ & 1826 & $94.9 \%$ & \\
\hline \multicolumn{10}{|l|}{ Smoking Behavior } \\
\hline No & 516 & $89.9 \%$ & 5134 & $95.9 \%$ & 8115 & $97.7 \%$ & 3790 & $99.2 \%$ & \\
\hline Yes & 58 & $10.1 \%$ & 218 & $4.1 \%$ & 192 & $2.3 \%$ & 30 & $0.8 \%$ & \\
\hline
\end{tabular}

Note: ${ }^{*} \mathrm{p}<0.05 ;{ }^{* *} \mathrm{p}<0.01 ;{ }^{* * *} \mathrm{p}<0.001$. 
Table 2. Results of binary logistic regression of LBW among female worker who had given birth in the last 5 years in Indonesia $(n=18,061)$

\begin{tabular}{|c|c|c|c|c|}
\hline \multirow{2}{*}{ Predictor } & \multicolumn{4}{|c|}{ Low Birth Weight } \\
\hline & $\mathbf{P}$ & OR & Lower Bound & Upper Bound \\
\hline Education Level: No education & - & - & - & - \\
\hline Education Level: Primary & 0.163 & 0.747 & 0.496 & 10.126 \\
\hline Education Level: Secondary & $* * 0.006$ & 0.561 & 0.370 & 0.850 \\
\hline Education Level: Higher & $* * * 0.000$ & 0.414 & 0.265 & 0.645 \\
\hline Age group of respondents: $15-19$ & - & - & - & - \\
\hline Age group of respondents: $20-24$ & 0.409 & 1.292 & 0.704 & 2.369 \\
\hline Age group of respondents: $25-29$ & 0.814 & 1.074 & 0.592 & 1.950 \\
\hline Age group of respondents: $30-34$ & 0.711 & 1.119 & 0.617 & 2.027 \\
\hline Age group of respondents: $35-39$ & 0.970 & 0.989 & 0.543 & 1.799 \\
\hline Age group of respondents: $40-44$ & 0.604 & 1.176 & 0.638 & 2.166 \\
\hline Age group of respondents: $45-49$ & 0.398 & 1.348 & 0.674 & 2.698 \\
\hline Marital status: Never in union/Divorced/Widowed & - & - & - & - \\
\hline Marital status: Married/Living with partner & 0.627 & 1.080 & 0.791 & 1.474 \\
\hline Wealth status: Poorest & - & - & - & - \\
\hline Wealth status: Poorer & 0.152 & 0.863 & 0.705 & 1.056 \\
\hline Wealth status: Middle & 0.103 & 0.841 & 0.684 & 1.035 \\
\hline Wealth status: Richer & $* * 0.002$ & 0.708 & 0.568 & 0.882 \\
\hline Wealth status: Richest & $* * 0.006$ & 0.722 & 0.572 & 0.912 \\
\hline ANC visits: $<4$ times & - & - & - & - \\
\hline ANC visits: $\geq 4$ times & $* * * 0.000$ & 0.603 & 0.497 & 0.730 \\
\hline Smoking behavior: No & - & - & - & - \\
\hline Smoking behavior: Yes & 0.727 & 1.081 & 0.699 & 1.672 \\
\hline
\end{tabular}

Note: ${ }^{*} \mathrm{p}<0.05 ;{ }^{* *} \mathrm{p}<0.01 ;{ }^{* * *} \mathrm{p}<0.001$.

A high level of education is one of the outputs of women's empowerment. Better education has an impact on maternal nutrition and reduces the incidence of $\mathrm{LBW}^{16,17}$. Several previous studies have informed that a good level of education is a major predictor of performance in the health sector ${ }^{18,19}$. On the other hand, poor education is an obstacle for the health sector to produce quality output ${ }^{20,21}$.

Apart from the education level, the analysis also found two other variables as predictors of LBW among female workers in Indonesia. First, wealth status. The richer female worker has a 0.708 times chance compared to the poorest female worker to give birth to LBW babies (OR 0.708 ; $95 \%$ CI $0.568-0.882$ ). The richest female worker has a probability of 0.722 times compared to the poorest female worker to give birth to LBW babies (OR 0.722; 95\% CI 0.572-0.912). Wealth status as a predictor of LBW because it relates to food availability in the household. The poorer a family, the lower the food availability ${ }^{22}$. Several studies provide consistent findings. Some of them were carried out in India, Ethiopia, Bangladesh, and Pakistan ${ }^{23-26}$.

The second, ANC visits. Female workers who made complete ANC visits ( $\geq 4$ times) during their pregnancy were 0.603 times more likely than female workers who made incomplete ANC visits ( $<4$ times) to deliver LBW babies (OR $0.603 ; 95 \%$ CI $0.497-0.730$ ). The results of this analysis inform that carrying out complete ANC visits is a protective factor for LBW among female workers in Indonesia. 
Conducting ANC visits as recommended by the Ministry of Health at least 4 times during pregnancy will monitor the health of pregnant women properly ${ }^{27}$. If there is a risk of pregnancy, for example, the mother is underweight, interventions can be immediately carried out to provide the best delivery output for the mother and the baby ${ }^{28}$.

\section{Conclusions}

Based on the research results, it can be concluded that the education level is a predictor of LBW among female workers in Indonesia. The higher the education level, the lower the possibility of female workers to have LBW babies in Indonesia.

Acknowledgments: The author would like to thank the ICF International, who has agreed to allow the 2017 IDHS data to be analyzed in this article.

\section{Source of Funding: Self-funding}

Conflict of Interest: The authors declare no conflict of interest, financial or otherwise.

Ethical Clearance: The 2017 IDHS has received ethical clearance from the National Ethics Commission. Utilization of the 2017 IDHS data in this study has been permitted by ICF International through its website: https://dhsprogram.com/data/new-user-registration.cfm.

\section{References}

1. European Agency for Safety, at Work (EU-OSHA) $\mathrm{H}$. Risks and trends in the safety and health of women at work. EU-OSH. 2011;1-8.

2. Davidson PM, McGrath SJ, Meleis AI, Stern P, DiGiacomo M, Dharmendra T, et al. The Health of Women and Girls Determines the Health and Well-Being of Our Modern World: A White Paper From the International Council on Women's Health Issues. Health Care Women Int. 2011 Oct;32(10):870-86.

3. Bartley KA, Underwood BA, Deckelbaum RJ. A life cycle micronutrient perspective for women's health. Am J Clin Nutr. 2005 May;81(5):1188S1193S.

4. Banerjee B. Physical hazards in employment and pregnancy outcome. Indian $\mathrm{J}$ Community Med. 2009;34(2):89-93.

5. Smith LC, Ramakrishnan U, Ndiaye A, Haddad L, Martorell R. The importance of women's status for child nutrition in developing countries. Research Report of the International Food Policy Research Institute. 2003. 1-164 p.

6. Worldbank. Labor force participation rate, female ( $\%$ of female population ages $15+$ ) (modeled ILO estimate).

7. Organization IL. Care Work And Care Jobs For The Future Of Decent Work. Care Work and Class: Domestic Workers' Struggle for Equal Rights in Latin America. 2012. 1-10 p.

8. UNICEF. Women Work UNICEF's approach to women's paid and unpaid work. 2019;1-9.

9. Suparmi S, Chiera B, Pradono J. Low birth weights and risk of neonatal mortality in Indonesia. Heal Sci J Indones. 2016;7(2):113-7.

10. Mahmoodi Z, Karimlou M, Sajjadi H, Dejman M, Vameghi M, Dolatian M, et al. Association of maternal working condition with low birth weight: The social determinants of health approach. Ann Med Health Sci Res. 2015;5(6):385.

11. Xu X, Ding M, Li B, Christiani DC. Association of rotating shiftwork with preterm births and low birth weight among never smoking women textile workers in China. Occup Environ Med. 1994 Jul;51(7):470-4.

12. Khan JR, Islam MM, Awan N, Muurlink O. Analysis of low birth weight and its co-variants in Bangladesh based on a sub-sample from nationally representative survey. BMC Pediatr. 2018;18(1):19.

13. Mahumud RA, Sultana M, Sarker AR. Distribution and determinants of low birth weight in developing countries. J Prev Med Public Heal. 2017;50(1):1828.

14. Sharma M, Mishra S. Maternal risk factors and consequences of low birth weight in Infants. IOSR J Humanit Soc Sci. 2013;13(4):39-45.

15. World Health Organization. Global Nutrition Targets 2025: Low birth weight policy brief [Internet]. Geneva; 2014. Available from: https://www.who.int/nutrition/publications/ globaltargets2025_policybrief_lbw/en/

16. Kabir A, RashidMM, Hossain K, Khan A, Sikder SS, Gidding HF. Women's empowerment is associated with maternal nutrition and low birth weight: Evidence from Bangladesh Demographic Health Survey. BMC Womens Health. 2020;20(1):Article number 93. 
17. Shome S, Pal M, Bharati P. Influence of maternal autonomy and socioeconomic factors on birth weight of infants in India. Malays $\mathrm{J}$ Nutr. 2018;24(1):35-46.

18. Ipa M, Widawati M, Laksono AD, Kusrini I, Dhewantara PW. Variation of preventive practices and its association with malaria infection in eastern Indonesia: Findings from community-based survey. PLoS One. 2020;15(5):e0232909.

19. Wulandari RD, Laksono AD. Education as predictor of the knowledge of pregnancy danger signs in Rural Indonesia. Int J Innov Creat Chang. 2020;13(1):1037-51.

20. Laksono AD, Wulandari RD. The Barrier to Maternity Care in Rural Indonesia. J Public Heal From Theory to Pract. 2020;Online First.

21. Rohmah N, Yusuf A, Hargono R, Laksono AD, Masruroh, Ibrahim I, et al. Determinants of teenage pregnancy in Indonesia. Indian $\mathrm{J}$ Forensic Med Toxicol. 2020;14(3):2080-5.

22. Laksono AD, Ibad M, Mursita A, Kusrini I, Wulandari RD. Characteristics of mother as predictors of stunting in toddler. Pakistan J Nutr. 2019;18(12):1101-6.
23. Banerjee A, Singh AK, Chaurasia H. An exploratory spatial analysis of low birth weight and its determinants in India. Clin Epidemiol Glob Heal. 2020;8(3):702-11.

24. Alemayehu GM, Chernet AG, Dumga KT. Determinants of child size at birth and associated maternal factor in gurage zone. J Reprod Infertil. 2020;21(2):138-45.

25. Karim MR, Mondal MNI, Rana MM, Karmaker $\mathrm{H}$, Bharati P, Hossain MG. Maternal factors are important predictors of low birth weight: Evidence from Bangladesh demographic \& health survey-2011. Malays J Nutr. 2016;22(2):257-65.

26. Khan A, Nasrullah FD, Jaleel R. Frequency and risk factors of low birth weight in term pregnancy. Pakistan J Med Sci. 2016;32(1):138-42.

27. Laksono AD, Rukmini R, Wulandari RD. Regional disparities in antenatal care utilization in Indonesia. PLoS One. 2020;15(2):e0224006.

28. Siramaneerat I, Agushybana F, Meebunmak Y. Maternal risk factors associated with low birth weight in Indonesia. Open Public Health J. 2018 Aug;11(1):376-83. 